\title{
LM35 Temperature Sensor Using LabVIEW and NI myDAQ
}

\author{
P. Sandeep, V. Prakasam
}

\begin{abstract}
The NI myDAQ component consists of input and output ports. To sense the temperature is necessary at a many places for example kitchen, refrigerators, air conditioners, storage rooms etc. At these spaces to sense the temperature and its appropriate hint is required since it can basis serious complications otherwise. For example, if the temperature in the food room room is greater than an accustomed threshold, it will be damaging for all of the food objects. We can similarly consider "Fire Alarm" which is an example of temperature sensor. This paper offers the evidence about how to use the Labview for LM35 temperature sensor using NI myDAQ.
\end{abstract}

Keywords: NI, myDAQ, Labview, Fire Alarm, LM35.

\section{INTRODUCTION}

NI short for National Instruments, the NI myDAQ is one of Labview component which is low cost portable device and DAQ shorts for data acquisition. The NI myDAQ is used to amount and examine real world signals which is the software devices. NI myDAQ is ultimate for travelling electronics and attractive sensor quantities. Collective with NI LabVIEW on the Personal Computer/Laptop, students can investigate and practice acquired signals and control humble processes anytime, anywhere. The figure 1 shows the physical appearance of NI myDAQ device.

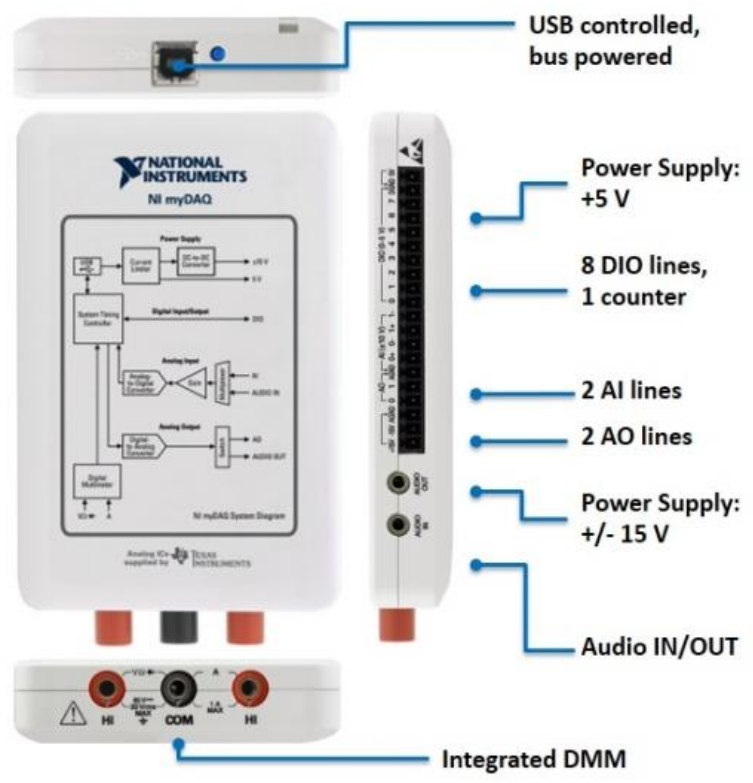

Fig. 1. The appearance of NI myDAQ

Revised Manuscript Received on October 15, 2019.

Mr. P. Sandeep, ECE, Vignan Institute of Technology and Science, Deshmukhi, Hyderabad, Telangana, India. (E-mail: pingili.sandeep@gmail.com)

Mr. V. Prakasam, ECE, Vignan Institute of Technology and Science, Deshmukhi,Hyderabad, Telangana, India.(E-mail: vprn2274@gmail.com)
The major parts of NI myDAQ are:

$>\quad$ Analog input - AI

$>\quad$ Analog output - AO

$>\quad$ Digital input and output - DIO

$>$ Audio

$>\quad$ Power supplies and

$>\quad$ Digital multi meter (DMM) functions in a compact USB device.

NI myDAQ permits for existent engineering and, when united with NI LabVIEW and Multisim, provides operator the power to sample systems and examine circuit's exterior of the allocution. Eight corporate engineering devices mount with the NI ELVISmx hardware driver.

\begin{tabular}{|l|c|c|l|}
\hline \multicolumn{1}{|c|}{ Signal Name } & Reference & Direction & \multicolumn{1}{|c|}{ Description } \\
\hline \hline AUDIO IN & - & Input & $\begin{array}{l}\text { Audio Input - Left and right audio } \\
\text { inputs on a stereo connector }\end{array}$ \\
\hline AUDIO OUT & - & Output & $\begin{array}{l}\text { Audio Output - Left and right audio } \\
\text { outputs on a stereo connector }\end{array}$ \\
\hline+15 V/-15V & AGND & Output & +15 V/-15 V power supplies \\
\hline AGND & - & - & $\begin{array}{l}\text { Analog Ground-Reference terminal } \\
\text { for AI, AO, +15 V, and -15 V }\end{array}$ \\
\hline AO 0/AO 1 & AGND & Output & Analog Output Channels 0 and 1* \\
\hline $\begin{array}{l}\text { AI 0+/AI 0-; } \\
\text { AI 1+/AI 1- }\end{array}$ & AGND & Input & Analog Input Channels 0 and 1 \\
\hline $\begin{array}{l}\text { DIO <0..7 } \\
\text { DGND }\end{array}$ & $\begin{array}{l}\text { Input or } \\
\text { Output }\end{array}$ & $\begin{array}{l}\text { Digital I/O Signals-General-purpose } \\
\text { digital lines or counter signals }\end{array}$ \\
\hline $\begin{array}{l}\text { DGND } \\
\text { PFI 0/ } \\
\text { CTR 0 SOURCE }\end{array}$ & - & - & $\begin{array}{l}\text { Digital Ground-Reference for the DIO } \\
\text { lines and the +5 V supply }\end{array}$ \\
\hline $\begin{array}{l}\text { PFI 1/ } \\
\text { CTR 0 GATE }\end{array}$ & - & - & $\begin{array}{l}\text { Digital I/O, line 0; PFI 0, Default } \\
\text { function: Counter 0 Source }\end{array}$ \\
\hline $\begin{array}{l}\text { PFI 2/ } \\
\text { CTR 0 AUX }\end{array}$ & - & - & $\begin{array}{l}\text { Digital I/O, line 1; PFI 1, Default } \\
\text { function: Counter 0 Gate }\end{array}$ \\
\hline $\begin{array}{l}\text { PFI 3/ } \\
\text { CTR 0 OUT }\end{array}$ & - & - & $\begin{array}{l}\text { Digital I/O, line 2; PFI 2, Default } \\
\text { function: Counter 0 Aux }\end{array}$ \\
\hline $\begin{array}{l}\text { PFI 4/ } \\
\text { FREQ OUT } \\
\text { function: Counter 0 Out }\end{array}$ \\
\hline 5V & - & $\begin{array}{l}\text { Digital I/O, line 4; PFI 4, Default } \\
\text { function: Frequency Output }\end{array}$ \\
\hline
\end{tabular}

Table 1: Screw Terminal Signal Descriptions. 


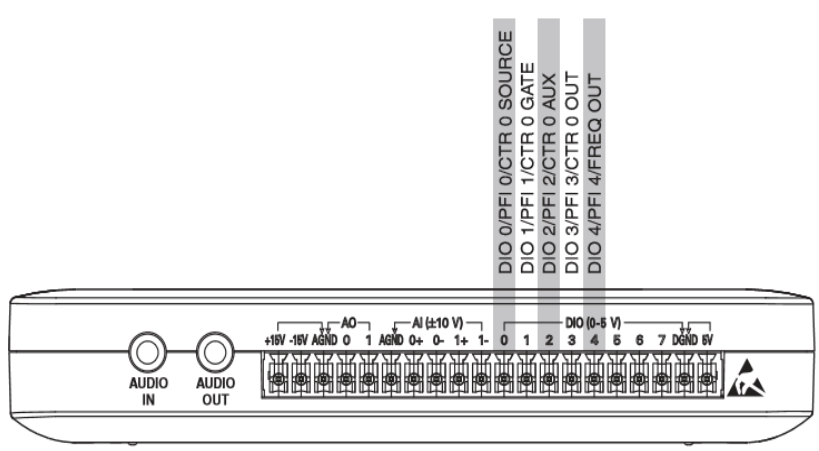

Fig. 2. NI myDAQ 20-Position Screw Terminal I/O Connector.

The 20-Position Screw Terminal I/O Connector of NI myDAQ shown in figure 2 . This figure 2 consists of various parts that are audio, AI, AO, DIO, GND, and power signals retrieved through the $3.5 \mathrm{~mm}$ audio port and screw terminal connections. Table I, shows the screw terminal explanation of NI myDAQ.

\section{LM35 TEMPERATURE SENSOR}

Temperature control is significant for parting and return processes, and temperature must be preserved within restrictions to safeguard safe and reliable task of process apparatus. The temperature sensor is endangered from the process resources to check intervention with correct sensing and to remove impairment to the sensor. Thus, selected physically solid, chemically resistant fence occurs between the process and sensor.

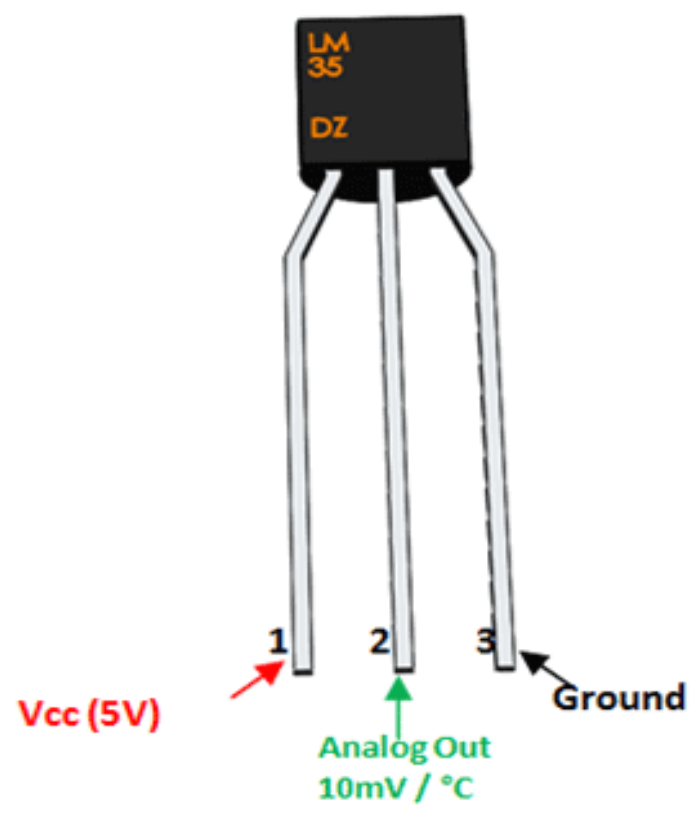

Fig. 3. LM35 Temperature sensor.

The LM35 succession are precision united circuit temperature strategies with a voltage of output directly proportional to centigrade temperature. The LM35 temperature sensor component shown in below figure 3 , the leading benefit over linear temperature devices standardized in Kelvin, as the user is not essential to remove an enormous nonstop voltage from the output to get suitable centigrade mounting. The LM35 does not need any peripheral adjustment or decoration to deliver classic accuracies of $\pm 1 / 4{ }^{\circ} \mathrm{C}$ at room temperature and $\pm 3 / 4{ }^{\circ} \mathrm{C}$ over a full $-55{ }^{\circ} \mathrm{C}$ to $150{ }^{\circ} \mathrm{C}$ temperature choice.

LM35 sensor consists of 3 pins, pin 1 is connects to Vcc for power supply from the NI myDAQ $+15 \mathrm{v}$, pin2 is connects to the analog pin A0 of the NI myDAQ and third pin (pin3) is connects to the ground of the NI myDAQ.

\section{NI MYDAQ AUDIO EQUALIZER METHODS}

\section{A. DAQ Assistant Express VI}

It consists of Creates, edits, and runs tasks using NIDAQmx. Denote to the NI-DAQmx Readme for a whole listing of devices NI-DAQmx supports.

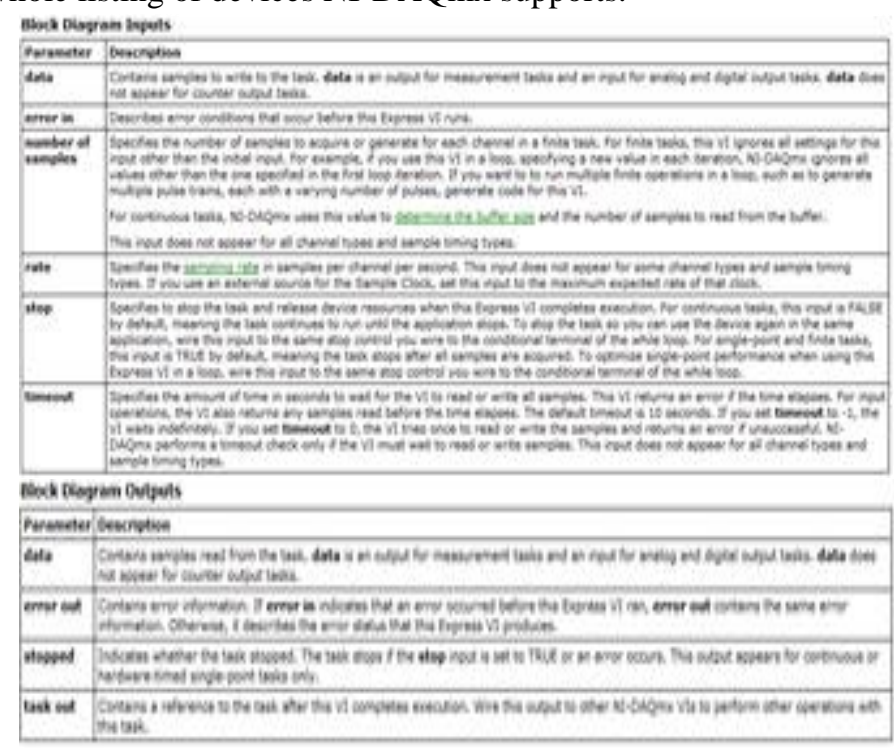

\section{NI MYDAQ CONNECTION PROCEDURE AND RESULT ANALYSIS}

Here, we are using LM35 temperature sensor, the LM35 temperature sensor production voltage varies linearly by temperature, and is directly proportional to temperature. The characteristics of LM35 sensor are:

1. Measureable range is $-55^{\circ}$ to $150^{\circ}$

2. Linear with $0.5^{0}$ certified accuracy at $+25^{0}$

$>$ In this project, we are used $+\mathrm{Vs}$ used is $15 \mathrm{~V}$

$>\quad$ The production at $36 \operatorname{deg} . \mathrm{C}$ is $0.36 \mathrm{~V}$ and the production at $21^{0}$ is $0.21 \mathrm{~V}$

$>\quad$ The upstairs calculations help as the strategy equalities for the block diagram of LABVIEW. 


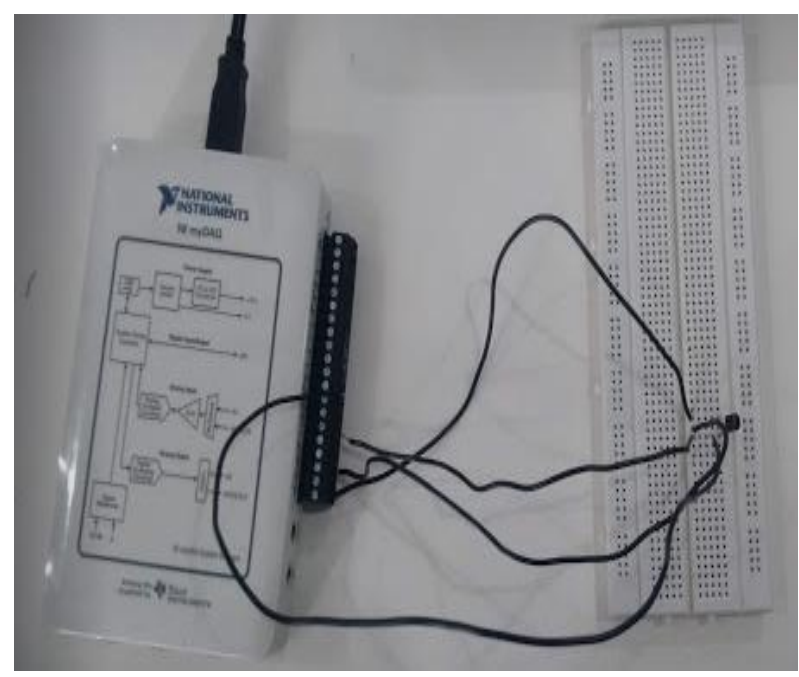

Fig. 4. Interfacing with NI myDAQ.

The Labview interfacing with NI myDAQ shown in below figure 4 . The NI myDAQ external setup that is hardware and software setup shown in below figure 5 . After regarding the path as shown in the figure 5, the output of Analog is working by AI0 channel of myDAQ, the source voltage to LM35 is assumed from the static voltage $+15 \mathrm{~V}$ from myDAQ.

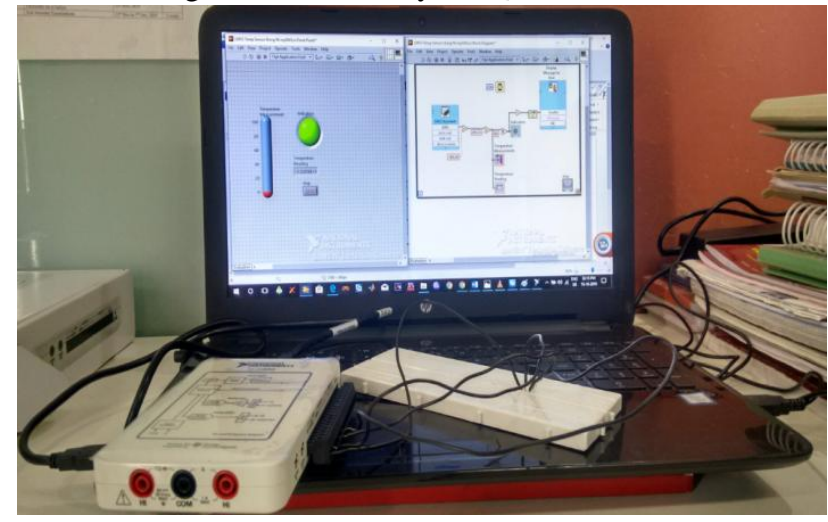

Fig. 5. Hardware and Software setup.

After joining the exterior hardware, then plan the interior programming of LabVIEW. First design the front panel. On the Front Panel, residence two Numeric Indicators (Temperature Reading) and a Thermometer (Temperature Measurement) and one Round LED (Indication). The temperature measurement minimum range 0 and maximum range 100. Figure 6 shows the proposed front panel design.

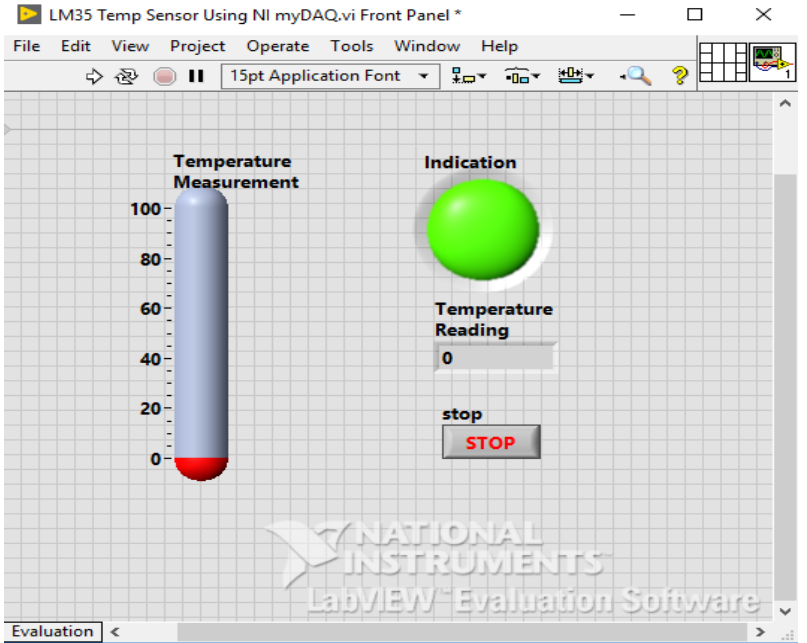

Fig. 6. Front panel design.

After completion of font panel design, we can carry on to plan its block diagram for consecutively the program, that we used a loop structure. On block diagram panel, right click on the block diagram $\rightarrow$ Express $\rightarrow$ Input $\rightarrow$ DAQ Assist. Double click on the DAQ Assistant. The Create New Express Task window will be opened. Select Acquire Signals $\rightarrow$ Analog Input $\rightarrow$ Temperature $\rightarrow$ Thermocouple.

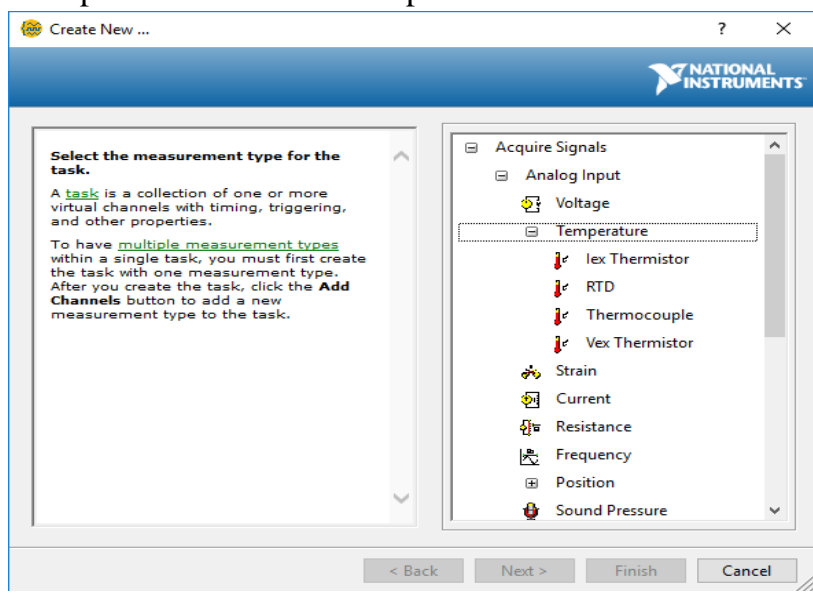

Select the Thermocouple. In this select the ai0, the important of this channel is to read the data from. This look like to one of the screw terminal connections on the device. Finally Click the Finish button. The DAQ Assistant dialog box will displayed on the screen.

After the decision of interface with NI myDAQ, using Labview, the input of analog data of DAQ is managed and standardized to display the accurate temperature by multiplying the DAQ Assistant production with a numeric constant '100'. When the temperature is less than $40^{\circ}$, green color light will be observable in labview front panel as shown figure 9. When the temperature more than $40^{\circ}$, red color light will be observable in labview front panel and a negotiation box looks as shown in the figure 10, which indicating 'DANGER!!!!!!'. 


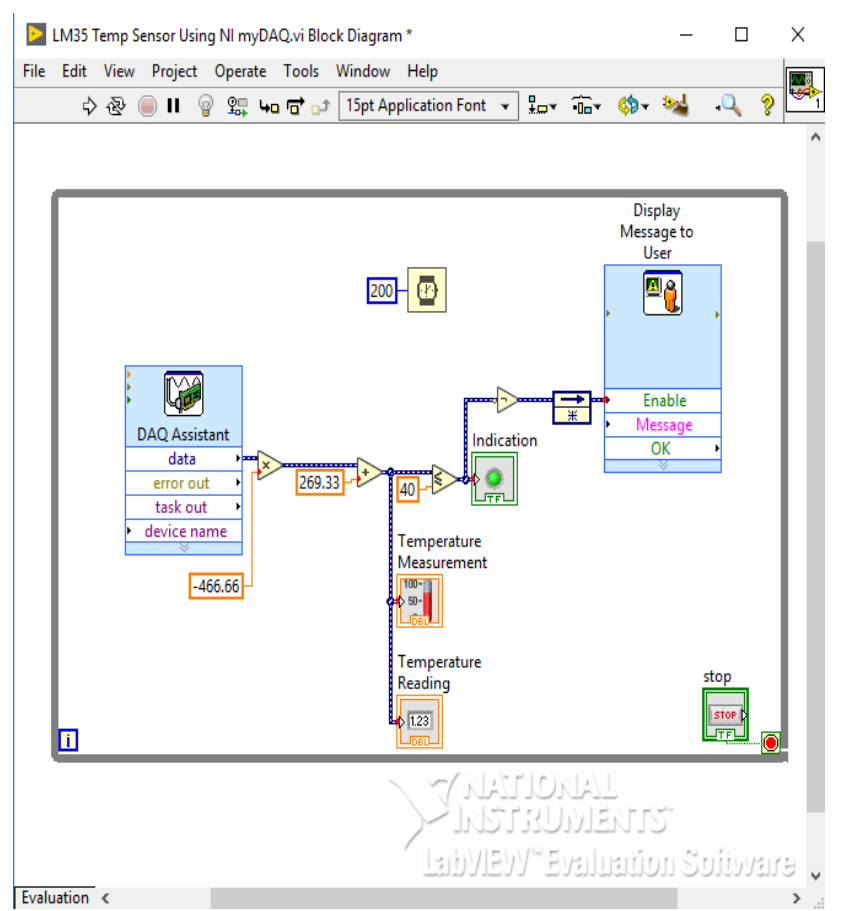

Figure 7: block diagram panel design.

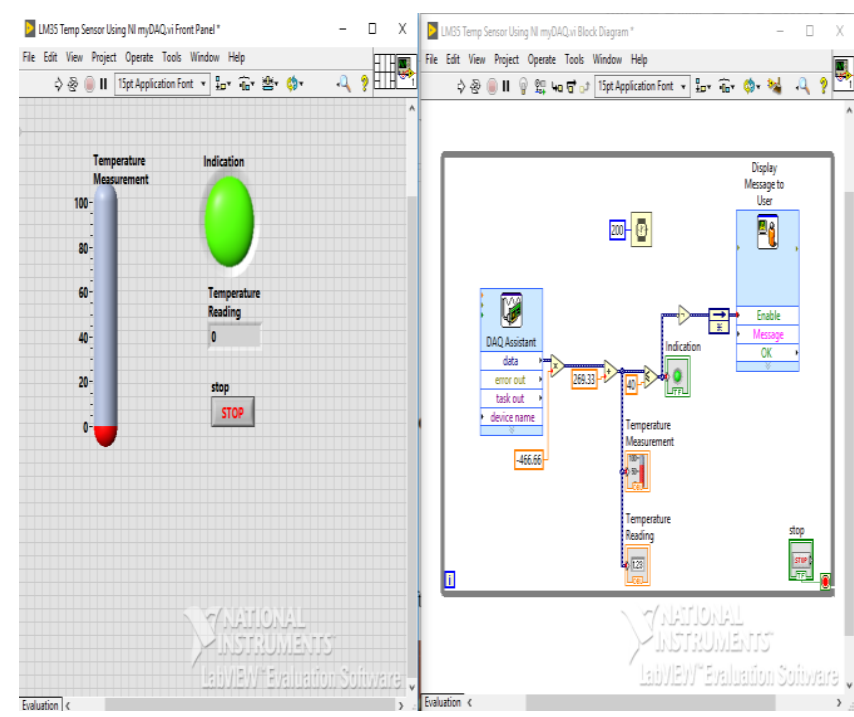

Figure 8: Front panel and block diagram panel design.

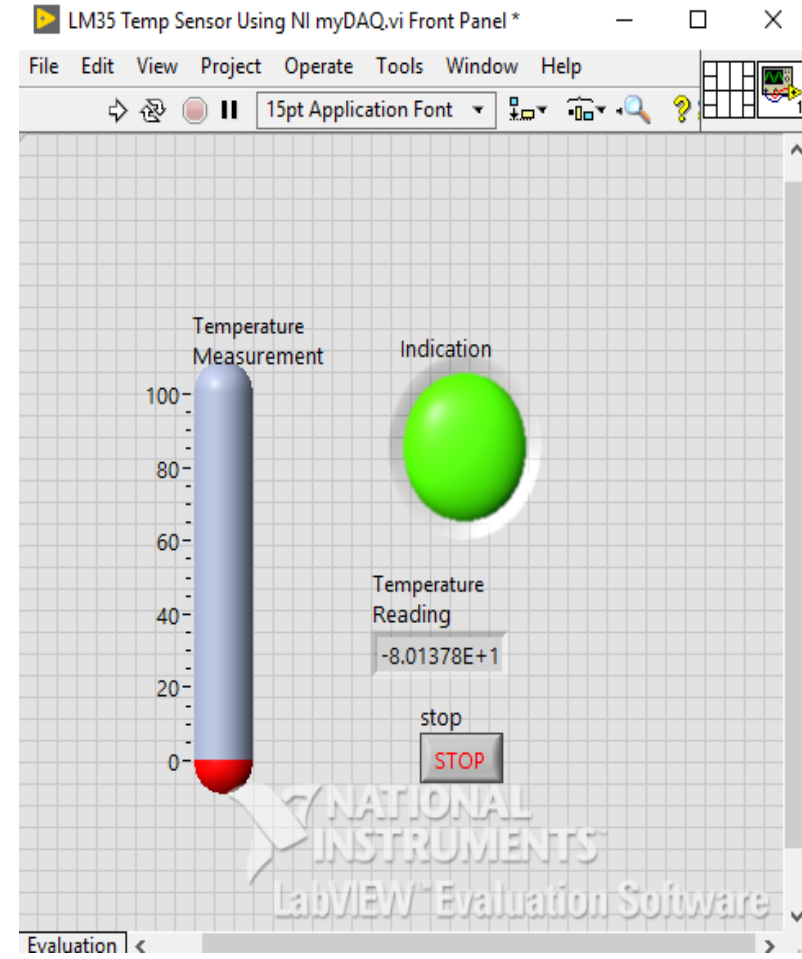

Figure 9: Result of the program running when the temperature is $<40$ deg. $C$.

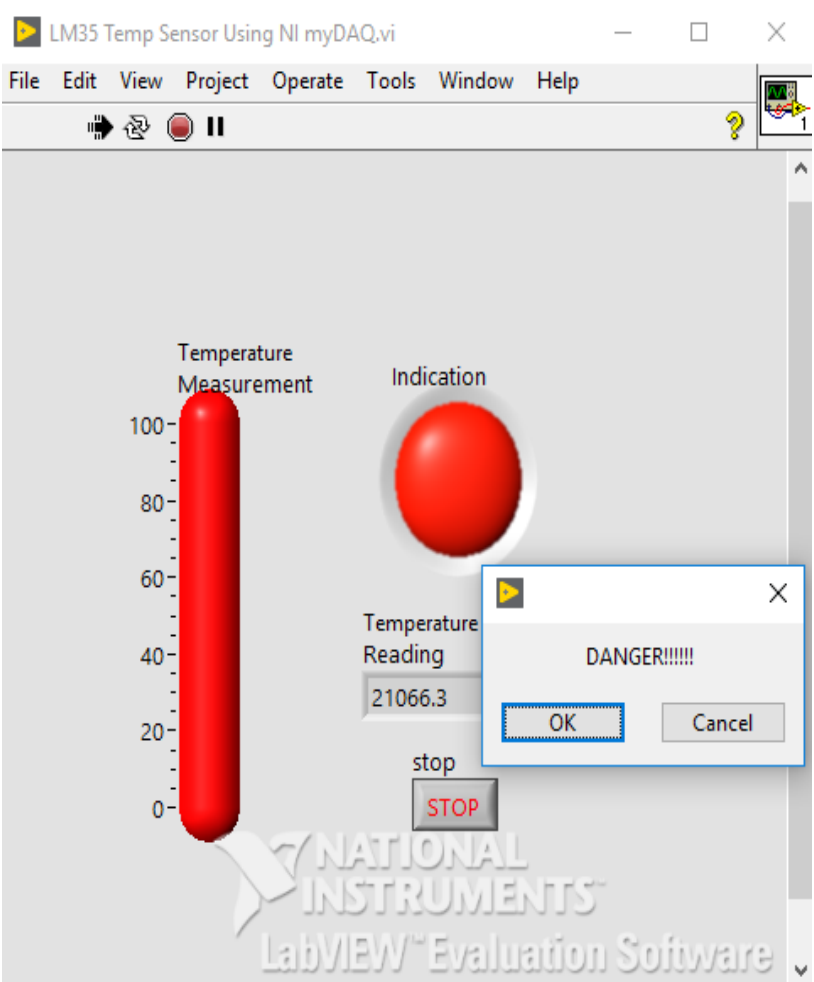

Figure 10: Result of the program running when the temperature is $>40 \mathrm{deg} . \mathrm{C}$.

\section{CONCLUSION}

Here, we used LM35 sensor, when the temperature is less than

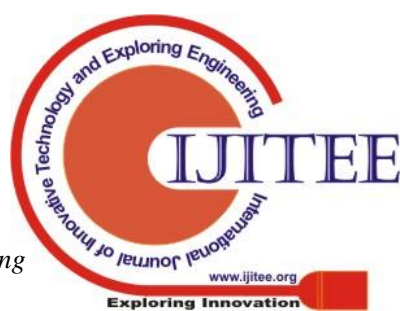


$40 \mathrm{deg}$., the green light turned on and the temperature is greater $40 \mathrm{deg}$., the red light turned on. The red light indicates the 'DANGER!!!!!!'. The main important application of LM35 is temperature and output voltage are directly proportional relation. This temperature sensor mainly used in home application, oil exploration, hot air balloons, GPS devices and battery systems.

\section{REFERENCES}

1. Jim Baker.How to call win32 Dynamic link Libaries(DLLs)from LabVIEW. National Instruments Notes 088. www.ni.com.

2. Integrating the Internet into Your Measurement System-Data Socket Technical Overview.USA.

3. Based on NImyDAQ Sound Processing System, College of Electronics and Information Engineering,ChangchunUniversity,Changchun,chin a.

4. Using LabVIEW to Measure Temperature with a Thermistor, C. Briscoe and W. Dufee, University of Minnesota.

5. P. A. H. Vardhini, "Analysis of integrator for continuous time Digital sigma Delta ADC on Xilinx FPGA," 2016 International Conference on Electrical, Electronics, and Optimization Techniques (ICEEOT), Chennai, 2016, pp. 26892693.

6. Real Time Temperature Monitoring Using LABVIEW and Arduino, Vaibhav M. Davande1, Pradeep C. Dhanawade2, Vinayak B. Sutar3, International Journal of Innovative Research in Computer and Communication Engineering, Vol. 4, Issue 3, March 2016.

\section{AUTHORS PROFILE}

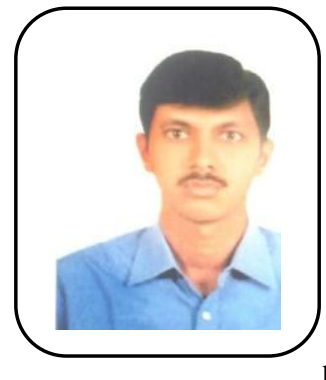

P.Sandeepreceived B.E degree from VTU, Belgaum, M.Tech degree in VLSID from Sathyabama University and pursuing p.hD. He is currently an Assistant Professor in the department of Electronics and Communication Engineering at Vignan institute of technology and sciences, deshumuki. His research interests Signal processing, image processing, Analog Electronics engineering, Low Power and High Speed Systems and VLSI Design.

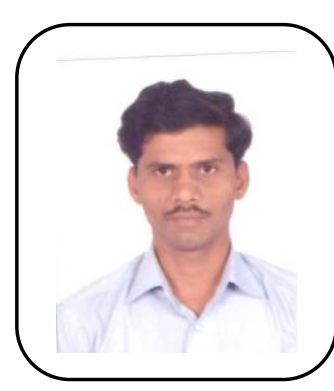

V. Prakasamreceived B.Tech degree from JNTUA, M.Tech degree in VLSISD from JNTUK and pursuing p.hD. He is currently an Assistant Professor in the department of Electronics and Communication Engineering at vignan institute of technology and sciences, deshumuki. His research interests Signal processing, image processing, Microwave Engineering and RF Engineering. 